\title{
7
}

\section{ONCE UPON COVID-19}

\section{A tale of misleading information going viral}

\author{
Alice Hazelton
}

\section{Introduction}

First detected in Wuhan, China, a pneumonia of an unknown cause was reported to the World Health Organization (WHO) country office in China on 31 December 2019. The outbreak was declared a Public Health Emergency of International Concern on 30 January 2020 and on 11 February 2020, the WHO announced a name for the new coronavirus disease: Covid-19, the word that will define 2020 for many of us. One month later, "deeply concerned both by the alarming levels of spread and severity", the WHO declared Covid-19 a pandemic (World Health Organization 2020a).

Covid-19 is the name of the infectious disease caused by the virus known as severe acute respiratory syndrome coronavirus 2 (Sars-CoV-2). At the time of writing, on 6 June 2020, the virus has infected over 6.75 million people in almost every country and claimed the lives of 395,328 people. Almost three million people have recovered after the infection (Johns Hopkins University 2020). With differing testing capabilities across different jurisdictions, the true toll of the virus on human lives will not be known for some time, if ever.

Along with an escalation of cases and deaths, life as we know it has ground to a halt. Millions of people around the world have found themselves under lockdown measures and quarantined to their own homes. Border closures and travel bans have severely disrupted supply chains, businesses are teetering on the brink of collapse, and record levels of unemployment loom. The magnitude and speed of collapse in economic activity is unlike anything ever experienced for many of us and, as long as containment measures are necessary to further prevent the spread of Covid-19 or the development of therapeutics and vaccines comes about, the worse are the prospects for economic recovery. The 'Great Lockdown' will see the world economy experience the worst recession since the Great Depression (Gopinath 2020). 
As the virus has spread around the planet affecting both lives and livelihoods, so too has an overload of information, including misinformation - incorrect but not deliberately misleading - and disinformation - purposefully misleading (UNESCO 2018). Day-to-day conversation, social media feeds, front page news, television, and radio are dominated by stories about Covid-19 and it is becoming increasingly difficult to look past sensational headlines and separate facts from fiction. From tales of the virus starting with a woman eating bat soup, to the President of the United States touting drinking bleach as a cure (Taylor 2020), how does one know what to believe and what not to?

"We're not just fighting an epidemic; we're fighting an infodemic", Tedros Adhanom Ghebreyesus, Director-General of the WHO, said on 11 February 2020 at the Munich Security Conference in Germany, referring to the fact that fake news "spreads faster and more easily than this virus" (World Health Organization 2020b). Indeed, a lack of reliable information and trusted sources can be as dangerous as the virus itself. Inaccurate information does not only mislead people, but it can endanger lives by encouraging people to ignore public health advice, take unproven drugs, or refuse a vaccine, should one become available.

Written during the midst of the pandemic, this chapter aims to briefly document the rise of misinformation and disinformation related to Covid-19 to date and to consider some attempts to thwart it, along with offering suggestions for future work and discussion. As the situation is rapidly evolving and changing on a day-to-day basis, it is by no means an exhaustive account but instead showcases several illustrative examples. A thorough analysis should be undertaken if and when the pandemic subsides.

\section{History repeats itself: Disease narratives}

"We know that every outbreak will be accompanied by a kind of tsunami of information, but also within this information you always have misinformation, rumours, etc. We know that even in the Middle Ages there was this phenomenon," said Sylvie Briand of WHO's Health Emergencies Programme (Zarocostas 2020).

Misleading information is nothing new. Before diving into the details of the Covid-19 pandemic, it is perhaps worth briefly looking at what history tells us about the way news travels during outbreaks, why falsehoods originate, and how they spread. While a scientific approach is vital to helping us understand the virus itself, lessons from folklore - the study of culture - can offer an understanding of the reasons behind human behaviour; in this case, how and why inaccurate information spreads during disease outbreaks. Both approaches are equally important to the study of information dissemination, but it is often the difference between how the scientific world views or tells the story of an epidemic event - the evidence and the story that circulates in public discourse where rumours begin.

Only humans tell stories. In his unified theory of storytelling, Gottschall (2012) argues that stories help us navigate life's complex problems and have evolved over 
time to ensure our survival. He notes that, "Of course, our story instinct has a darker side. It makes us vulnerable to conspiracy theories, advertisements, and narratives about ourselves that are more 'truthy' than true" (Gotschall 2012).

Looking back at past epidemics reveals a similar truth about the role of storytelling and the ability of humankind to believe one story over another. In his 2014 book, An Epidemic of Rumours: How Stories Shape Our Perceptions of Disease, folklorist Jon D. Lee sets out to examine the story-making process that underlies the narratives which circulate, and draws an unparalleled similarity between historical and modern disease narratives.

Lee (2014) uses the severe acute respiratory syndrome (Sars) as a case study but suggests that one could easily replace the words Sars and China with H1N1 and Mexico and the same narratives would hold. Unsurprisingly, doing the same thing today with Covid-19 reveals that, once again, the same narratives have been recycled, modified only by specific details that are necessary to link the narrative to the current situation.

Where did it come from? How does it spread? How can it be prevented? How can it be treated? Why do we not have a cure? In the absence of scientific evidence as answers to such questions, humans have a natural tendency to create their own answers in the form of stories in a bid to fill the void. For example, to date, scientists have not determined the exact origins of the Sars-CoV-2 virus yet numerous stories are filling the void, including that the virus escaped from a laboratory at the Wuhan Institute of Virology (Singh et al. 2020) or that the United States military brought the virus to Wuhan (Sardarizadeh and Robinson 2020). During the Sars epidemic in 2003, in the absence of scientific evidence regarding the origins of the virus, similar narratives circulated, including that Saddam Hussein had released Sars as part of a biological warfare campaign (Lee 2014: 58).

Some studies on disease narratives have revealed the common themes that one is already seeing during the Covid-19 pandemic and that we can expect to see used again in future outbreaks. Rooted in how different social groups perceive and represent reality, themes of xenophobia, racism, government deception, secrecy, and misconduct are commonplace. All revolve around the emotion of fear, which fuels the spread of rumours as individuals within a particular group sharing a common belief system are likely to pass it on to members of the same group in order to warn them of danger and protect them (ibid.: 171). "Rumours are often grounded in prejudices and misunderstandings so old that they are not recognised as inaccurate, so any attempt to challenge the rumour inherently challenges deeply ingrained belief systems and ideas," states Lee (2014: 172).

In the absence of scientific evidence, rumours and disinformation serve the purpose of filling an information vacuum and this in itself is strong enough to continue to support the existence of the narrative. Eradicating false narratives is likely to take as long as it takes to eradicate the disease and this is evidenced from Lee's study on the Sars epidemic: "As soon as the virus disappeared and ceased to make headlines, the stories died" (ibid.: 173). 
It goes without saying that during public health emergencies this approach is not useful when evidence-based information is essential to contain the disease and ensure public safety. Unfortunately, there are already instances from the Covid-19 pandemic where misleading information has resulted in unnecessary death. Just one example is that of a couple in Arizona, United States, who ingested chloroquine phosphate that they had left over from treating their koi fish, after seeing a televised briefing where President Trump talked about the benefits of chloroquine as a treatment for Covid-19. Chloroquine remains unproven as a treatment for Covid-19 and to great regret, the man died and the woman was left in a critical condition (BBC 2020).

If eradicating misleading information does not seem possible, then containment strategies are necessary, just like with the virus itself. When Lee wrote the book An Epidemic of Rumours in 2014, some previous studies had already shown that historical methods of controlling rumours were generally ineffective and resulted in further spread of the misleading information. Initial research at the time pointed to repeating evidence-based information rather than denying the misleading information: "For best results, the accurate, positive information should be repeated frequently to help solidify its public recognition and familiarity" (Lee 2014: 179). Certainly, organisations that disseminate information through society, such as the media, have a role to play in adopting this approach, but, as the next section will show, the rise in social media use makes this task ever-more challenging.

\section{Social media as a disease vector}

While many of the themes surrounding disease narratives and the associated misleading information undoubtedly appear to remain the same during the Covid-19 pandemic as in the past, the mediums by which such information spreads are different. Take the Internet, for example. One of our most transformative technologies had just 413 million active users in 2000, a number which has now grown to 4.57 billion people, encompassing $59 \%$ of the global population (Clement 2020).

Just over a decade after the creation of the Internet, 2004 marked the shift to Web 2.0 - a shift towards user-generated content - and with it, the dawn of social media. At the time, MySpace was the first social media site to reach one million active monthly users but fast-forward to today and Facebook, established in 2004, is the dominant social media platform with 2.3 billion users. YouTube, Instagram, and WeChat follow, with more than a billion users. Tumblr and TikTok come next, with over half a billion users (Roser et al. 2020). Note that during the Sars epidemic that formed the case study for Lee's (2014) book, social media was nascent.

As well as increased access to the Internet, the proliferation in the rise of smartphones around the world has led to a growing number of people spending time online and using social media platforms. In fact, one in three people worldwide and two thirds of all Internet users are on such platforms (Roser et al. 2020). 
It is not hard to imagine how misleading information can go viral with an increased use in social media, exacerbated by more time at home online due to lockdown situations around the world. One example from the current Covid-19 pandemic is that dubbed the 'Uncle with master's degree' post. The earliest version of the post was found on Facebook on 7 February and read, "My classmate's uncle and nephew, graduated with a master's degree, and work in Shenzhen Hospital. He is being transferred to study Wuhan pneumonia virus. He just called me and told me to tell my friends...". It was shared with a group called Happy People that had nearly 2000 members. The post included advice that is not scientifically or medically proven. Several days later, the same post was shared with minor modifications by a man in India and then again several weeks later by a man called Peter in the UK who had also altered the post to include new information. This time it caught the attention of fact-checking organisations but by then it was too late. The post had already been shared 350,000 times and contained false information like the virus hates the sun but also included factually accurate information about the importance of hand-washing. Since then, the post has spread across languages and the source has changed from the Uncle with the master's degree to board members of Stanford hospital and a friend's nephew in the military (Robinson and Spring 2020).

As we know from past studies of rumour formation and spread, it is likely that the post was not shared with bad intention but indeed through fear and with the intention to protect friends and family. After all, social media platforms allow likeminded people to connect from anywhere in the world. Therefore, the spread of misleading information can be faster and go further than ever before, especially when taking into consideration that platforms take account of user preferences and attitudes, and rely on algorithms to mediate and facilitate information, thus perpetuating the polarisation of views. Studies have shown that when polarisation is high, misleading information is high and can spread faster and further than evidence-based information (Vosoughi et al. 2018).

Recognising the extent of the 'infodemic' in hampering an effective public health response, the WHO, businesses, and governments around the world have united in their response to provide the public with trustworthy sources, reliable guidance, and evidence-based information. Specifically, the WHO established the Information Network for Epidemics (EPI-WIN) to "unite technical and social media teams working closely to track and respond to misinformation, myths and rumours and provide tailored information and evidence for action" (World Health Organization 2020c).

The WHO is tackling the infodemic under the four themes listed below:

1. The causes of the disease: How did it emerge and what is the reason?

2. The illness: what are the symptoms and how is it transmitted?

3. The treatment: How can it be cured?

4. The interventions: what is being done by health authorities or other institutions? 
W orking with some of the world's biggest search and social media companies, such as Facebook, Google, Tencent, Twitter, and others, the WHO is trying to counter the spread of rumours including that consuming ginger and garlic can prevent the virus, that the virus cannot survive hot weather, and that introducing bleach to your body will protect against Covid-19 (World Health Organization 2020d).

Over the last weeks and months, it's not been unusual to be directed to official guidance (based on evidence) when undertaking an Internet search for "Covid-19" or logging on to social media platforms. Facebook includes an 'Information Center' sharing official medical advice, Instagram delivers a pop-up urging US users to go to the website for the Centers for Disease Control and Prevention (CDC) - or UK users to the NHS - rather than look at the memes and pictures tagged with \#coronavirus, and on Pinterest, the only memes and infographics to be found related to Covid-19 are those made by internationally recognised organisations (Wong 2020). In an unprecedented move, Facebook and Twitter have both removed content from a head of state falsely stating that a drug could treat Covid-19 (Ball and Maxmen 2020). As of 5 March, Twitter introduced a new labelling system for tweets containing synthetic and manipulated media and, more recently, tweets containing potentially harmful, misleading information related to Covid-19 are also labelled (Roth and Pickles 2020).

All these efforts rely on fact-checkers at independent media organisations to verify and raise the alarm on misleading information. Back in January, 88 media organisations joined together to record their fact-checking activities with regards to information related to Covid-19. The database, which contained more than 6000 samples in May, is maintained by the International Fact-Checking Information Network - the Network is part of the Poynter Institute for Media Studies in St Petersburg, Florida (Ball and Maxmen 2020), and it is just one group among many which are banded together to sift through countless claims in a bid to weed out accurate, evidence-based information.

Despite the valiant efforts of social media platforms to control the narrative on Covid-19, misleading information continues to spread mostly on social media compared to other sources. An analysis conducted by Brennen and colleagues (2020) which looked at 225 pieces of information considered misleading by independent fact-checkers showed that, while the social media companies have removed or labelled misleading content, $58 \%$ of false posts remained active on Twitter, $27 \%$ on YouTube, and $24 \%$ on Facebook. It should also be noted that while independent fact-checking can go some way in identifying misleading sources of information, fact-checkers are limited in their resources and cannot assess the veracity of information that spreads in private channels, closed groups, and messaging applications; a phenomenon that misinformation scholar Joan Donovan refers to as "hidden virality' (Donovan 2020). She states that researchers have access to less than $2 \%$ of the spaces where misleading information circulates; this makes it impossible to investigate, let alone counter, the huge influx of misleading information that is circulating. 
While we know that misleading information is exacerbated by social media, it is not limited to these platforms. It should be noted that Brennen's (2020) analysis found that $20 \%$ of claims known to be false came 'top-down' from high-level politicians, celebrities, and prominent public figures, and $36 \%$ of these instances included speaking publicly or to the media.

Although the public is increasingly aware, and increasingly concerned, about the problem of misleading information (Fletcher et al. 2020), this new attitude does not equate to an ability to be less susceptible to misleading information. For that, science and scientists can help.

\section{Flattening the curve of misleading information through science}

While the Covid-19 pandemic to date has shown that a myriad of stakeholders from social media platforms to governments and public health authorities - are willing to step up their efforts to combat the spread of misleading information, raising the profile of evidence-based information can only go as far as how much individuals trust the source it is coming from.

"If people think the WHO is anti-American, or Anthony Fauci is corrupt, or that Bill Gates is evil, then elevating an alternative source does not do much - it just makes people think that platform is colluding with that source," says Renée diResta from the Stanford Internet Observatory in California (Ball and Maxmen 2020).

Some suggest that those sharing evidence-based information, such as public health authorities, could do a better job at explaining how the evidence base that ultimately resulted in public health recommendations was built up (Ball and Maxmen 2020). For example, rather than just sharing the results of scientific assessments, it would help to explain how and why the evidence was collected and evaluated. Indeed, Lee (2014: 186) concludes the final paragraph of his book by stating that, "Unfortunately no herbal remedies can fix the media; no vaccines can cure racism. Only concerted, intelligent efforts to educate people in the delicate intricacies of cause-and-effect relationships stand any chance of succeeding." Therefore, the need to increase scientific literacy among different publics could not be a more urgent and important task.

Doing so could avoid widespread phenomena such as 'vaccine hesitancy', which has gained momentum over the years despite evidence that vaccines are effective in preventing infections by deadly diseases. (This indeed is an especially worrying trend considering that a vaccine, when developed, will likely contain the Covid-19 pandemic). Misleading information is also slowing prior momentum towards an international agreement on climate change, which will likely have disastrous consequences worldwide later this century (Hopf et al. 2019). The Covid-19 pandemic is just another instance in this string of recent examples where misleading information can result in harm. Indeed, in a 'post-truth' era, experts are also questioned and opinions towards some scientific issues remain polarised among religious and political lines. Without equipping individuals with the knowledge 
and skills necessary to be able to autonomously evaluate scientific evidence, we risk undermining trust in science and evidence-based decision-making for better outcomes.

But why should we trust scientific evidence? Since its introduction by Francis Bacon in the 17th century, the scientific method has evolved but is guided by unbiased observations that are evaluated for reproducibility and subjected to careful self-criticism before being offered for scrutiny by the scientific community through the peer review process and publication in scientific journals. If disproved, prevailing models and theories would be replaced by new ones more consistent with the contemporary state of knowledge (Hopf et al. 2019). More recently, historian of science Naomi Oreskes (2019) has argued that it is not necessarily the scientific method that makes science trustworthy, as many of us assume, but it's the 'social character' of science that makes it trustworthy: "All scientific claims are subject to tough scrutiny, and it's only the claims that pass this scrutiny that we can say constitute scientific knowledge." Scientific authority is not based on any individual, but rather on the collective wisdom of the community (Oreskes 2019). ${ }^{1}$

Science will provide us with an 'exit strategy' from the pandemic when a vaccine is finally developed, but until then researchers around the world are working to help understand the origins of the Sars-CoV-2 virus, how it spreads, what treatments are most effective, and indeed if a cure is possible. Sure, there are no definite answers to these questions yet but as more evidence is gathered and consensus built through the collective wisdom of the scientific community, public health advice is likely to change and adapt. As Hopf et al. (2019) note, "this provisional character of science is not a weakness but is one of the key reasons for its strength."

As purveyors of evidence, scientists and members of the broader scientific ecosystem have multiple roles to play when it comes to fighting both the Covid-19 pandemic and associated infodemic:

\section{- Contributing to knowledge and evidence}

Scientists around the world have mobilised, formed new collaborations and redirected their research agendas to help support the response to Covid-19. In fact, processes that normally take months or years have moved at lightning speed and researchers have already made progress in identifying the virus, deciphering its structure, testing treatments, and trialling a vaccine. In January, the first scientific paper related to Covid-19 was published but since then, scientific literature relating to Covid-19 has reached more than 23,000 papers and is doubling every 20 days according to one count (Brainard 2020).

As well as contributing to evidence to inform the public health response, research has an important role to play in charting the spread of misleading information related to the infodemic. Numerous studies are already underway including, for example, a team at the University of Southern California in Los Angeles sharing a data set containing more than 120 million tweets about Covid-19, and in Trento, Italy, a team at the Bruno Kessler Institute using automated software to track 
4.7 million tweets a day about Covid-19 to evaluate the content, determine where they were sent from, and to estimate their reliability (Ball and Maxmen 2020).

Finally, there is a need for a new research agenda into 'the science of science communication'. Future research should study the measures put in place by social media platforms and health authorities during Covid-19 to combat misleading information to see what effect they had. As we know, susceptibility to any information, whether evidence-based or not, is highly driven by cultural context, and scientists and scientific institutions need to use cultural literacy to better engage communities with science and its evidence. These communication and engagement strategies should themselves also be subject to analysis to better understand what works and what doesn't.

\section{- Communicating and engaging the public}

Just as important as explaining the evidence itself, is explaining the process it took to get there. It is also no secret that explaining science is complicated and unintentional communication errors can result in misleading information. One such example from the COVID-19 pandemic is when a German newspaper reported a study that was yet to undergo scientific peer review and ultimately led to a change in policy (Lahrtz and Serrao 2020).

During a time when we need individuals who can critically evaluate and clearly communicate evidence, it is discouraging to take note of the decline in both professional fact-checkers and science joumalists in newsrooms around the world (Scheufele and Krause 2019). As such, coverage of scientific issues has become the responsibility of political reporters, business writers, and journalists in non-scientific beats, sometimes leading to the dangerous phenomenon of "balance as bias" coined by Boykoff and Boykoff (2004): equal coverage and weighting is given to opposing views according to journalistic norms; this contributes to further exacerbate views not based on evidence, resulting in a biased account of the situation. For example, reporting on US elections involves giving equal weighting to opposing parties but reporting on climate change should not give equal weighting to climate scientists and those who do not believe in anthropogenic climate change. Science communicators and science journalists are well placed to undertake this job as they have been trained in how to properly evaluate evidence, interpret jargon, or report on statistics. Investment in these professions is urgently needed, as well as the upskilling of scientists in order to represent their own work in an accurate, engaging, and easy-to-understand manner.

Education systems should also be reformed to place more emphasis on the culture and values of science and its processes. Durant and Ibrahim (2001) also make an important point about the power of informal outreach and engagement with science and suggest that nations should celebrate the culture of science and its values of reasoning, openness, tolerance, and respect for scientific evidence, just as they celebrate the arts and humanities that enrich peoples' lives. With this in mind, it should not go unnoticed that traditional channels of science 
communication outside of the education system included newspapers, television, and science museums, which tend to reach more educated and higher income audiences. Going forward, it will be crucial to make sure that under-served audiences are also reached.

- Advocating for science and science literacy

As well as contributing to scientific knowledge and communicating the 'what' and 'how', scientists must advocate for science and be ambassadors for the scientific community at large. Scientists must be ready to stand up against misleading information and call out those who dismiss valid scientific evidence when they see it (Hopf et al. 2019). Increased and improved capacity for science communication and public engagement will help with this, but scientists remain important stakeholders in upholding and sharing these values with society at large.

\section{Conclusion}

Seven months on from when the first cases of Covid-19 were reported, the pandemic is far from over. A week before the end of June 2020 and the world is seeing some of the biggest numbers of daily cases while countries remove lockdown measures in a bid to restart their economies. The aims of this chapter were to briefly document the rise of misinformation and disinformation related to Covid-19 along with some of the attempts to-date to thwart it. It finished by offering thoughts on steps forward, which may well end up being undertaken in the time that it takes to publish this book. When the pandemic finally subsides, I look forward to working with others from different fields to analyse the story of Covid-19 in further detail, take note, and share the lessons learned in the hope that history will not repeat itself in the same way again.

\section{Note}

1 It should not go unmentioned that during the Covid-19 pandemic there have been instances of influential scientific papers being retracted. For example, a study into the efficacy of hydroxychloroquine - touted as a treatment by several public figures - was found to be flawed, retracted, and clinical trials were halted (Davey and Kirschgaessner 2020). One can only assume that the pressure to find a treatment resulted in some editorial oversight and in normal circumstances this would not, and should not, happen. The chapter is written on the assumption that proper checks and balances are in place to avoid these sorts of instances.

\section{References}

Ball, P., A. Maxmen (2020) 'The epic battle against coronavirus misinformation and conspiracy theories', Nature [online], 27 May 2020, www.nature.com/articles/d41586-02001452-z (last consulted on 5 June 2020).

BBC (2020) 'Coronavirus: Man dies taking fish tank cleaner as virus drug', BBC News, 24 March 2020 https:/ /www.bbc.com/news/52012242 (last consulted on 7 June 2020). 
Boykoff, M., J. Boykoff (2004) 'Balance as bias: global warming and the US prestige press', Global Environmental Change 14(2): 125-36.

Brainard, J. (2020) 'Scientists are drowning in COVID-19 papers. Can new tools keep them afloat?', Science, 13 May 2020, www.sciencemag.org/news/2020/05/scien tists-are-drowning-covid-19-papers-can-new-tools-keep-them-afloat (last consulted on 8 June 2020).

Brennen, J. et al. (2020) 'Types, sources, and claims of COVID-19 misinformation' Reuters Institute, University of Oxford, 7 April 2020, https://reutersinstitute.politics.ox.ac.uk/typessources-and-claims-covid-19-misinformation\#sources (last consulted on 6 June 2020).

Clement, J. (2020) 'Worldwide digital population as of April 2020', Statista, 4 June 2020, www.statista.com/statistics/617136/digital-population-worldwide/ (last consulted on 6 June 2020).

Conway, E., N. Oreskes (2010) Merchants of Doubt: How a Handful of Scientists Obscured the Truth on Issues from Tobacco Smoke to Global Warming, New York: Bloomsbury Press.

Davey, M., S. Kirschgaessner (2020) 'Surgisphere: Mass audit of papers linked to firm behind hydroxychloroquine Lancet study scandal', The Guardian, 10 June 2020, www. theguardian.com/world/2020/jun/10/surgisphere-sapan-desai-lancet-study-hydroxy chloroquine-mass-audit-scientific-papers (last consulted on 19 June 2020).

Donovan, J. (2020) 'Covid hoaxes are using a loophole to stay alive - even after content is deleted', MTT Technology Review, 30 April 2020, www.technologyreview. com/2020/04/30/1000881/covid-hoaxes-zombie-content-wayback-machine-disinfor mation/ (last consulted on 7 June 2020).

Durant, J., A. Ibrahim (2011), 'Celebrating the culture of science', Science 331(6022): 1242.

Fletcher, R. et al. (2020) 'Trust in UK government and news media COVID-19 information down, concerns over misinformation from government and politicians up', Reuters Institute, University of Oxford, 1 June 2020, https://reutersinstitute.politics.ox.ac.uk/ trust-uk-government-and-news-media-covid-19-information-down-concerns-overmisinformation (last consulted on 7 June 2020).

Gopinath, G. (2020) 'The Great Lockdown: Worst economic downturn since the Great Depression', IMFBlog, 14 April 2020, https://blogs.imf.org/2020/04/14/the-greatlockdown-worst-economic-downturn-since-the-great-depression/ (last consulted on 6 June 2020).

Gottschall, J. (2012) The Storytelling Animal: How Stories Make Us Human, Boston: Houghton Mifflin Harcourt.

Hopf, H. et al. (2019) 'Fake science and the knowledge crisis: Ignorance can be fatal', Royal Society Open Science 6: 190161, http://doi.org/10.1098/rsos.190161.

Johns Hopkins University (2020) 'COVID-19 Dashboard by the Center for Systems Science and Engineering (CSSE) at Johns Hopkins University (JHU)' Johns Hopkins University, https://coronavirus.jhu.edu/map.html (last consulted on 6 June 2020).

Lahrtz, S., M. F. Serrao (2020) 'Drosten, kekulé und Corona: Hahnenkampf ohne gewinner', Neue Zürcher Zeitung, 28 May 2020, www.nzz.ch/international/drosten-kekuleund-corona-hahnenkampf-ohne-gewinner-ld.1558276 (last consulted on 8 June 2020).

Lee, J.D. (2014) An Epidemic of Rumours: How Stories Shape Our Perceptions of Disease, Boulder: University Press of Colorado.

Oreskes, N. (2014) 'Why we should trust scientists', TEDSalon NY2014, available from: www.ted.com/talks/naomi_oreskes_why_we_should_trust_scientists (last consulted on 6 June 2020).

Oreskes, N. et al. (2019) 'Naomi Oreskes on Why Trust Science?' [online], 13 November 2019, https://press.princeton.edu/ideas/naomi-oreskes-on-why-trust-science (last consulted on 6 June 2020 ). 
Robinson, O., M. Spring (2020) 'Coronavirus: How bad information goes viral', BBC Trending, 19 March 2020 https://www.bbc.com/news/blogs-trending-51931394 (last consulted 4 June 2020).

Roser, M., H. Ritchie, E. Ortiz-Ospina, J. Hasell (2020) 'Coronavirus pandemic (COVID-19)', https://ourworldindata.org/coronavirus (last consulted on 6 June 2020).

Roth, Y., N. Pickles (2020) 'Updating our approach to misleading information', Tuitter, 11 May 2020, https://blog.twitter.com/en_us/topics/product/2020/updating-ourapproach-to-misleading-information.html (last consulted on 6 June 2020).

Sardarizadeh, S., O. Robinson (2020) 'Coronavirus: US and China trade conspiracy theories', BBC News, 26 April 2020, www.bbc.com/news/world-52224331 (last consulted on 6 June 2020).

Scheufele, D. A., N.M. Krause (2019), 'Science audiences, misinformation and fake news', Proceedings of the National Academy of Sciences 116(16): 7662-69.

Singh, M. et al. (2020) 'Trump claims to have evidence coronavirus started in Chinese lab but offers no details', The Guardian, 1 May 2020, www.theguardian.com/us-news/2020/ apr/30/donald-trump-coronavirus-chinese-lab-claim (last consulted on 6 June 2020).

Taylor, J. (2020) 'Bat soup, dodgy cures and "diseasology": The spread of coronavirus misinformation', The Guardian, 31 January 2020, www.theguardian.com/world/2020/ jan/31/bat-soup-dodgy-cures-and-diseasology-the-spread-of-coronavirus-bunkum (last consulted on 6 June 2020).

UNESCO (2018) Joumalism, Fake News \& Disinformation: Handbook for Joumalism Education and Training [online], Paris: UNESCO - Communication and Information Sector, https://en.unesco.org/fightfakenews (last consulted on 6 June 2020).

Vosoughi, S. et al. (2018) 'The spread of true and false news online', Science 359(6380): $1146-51$.

Wong, C. (2020) 'Tech giants struggle to stem "infodemic" of false coronavirus claims', The Guardian, 10 April 2020, www.theguardian.com/world/2020/apr/10/tech-giantsstruggle-stem-infodemic-false-coronavirus-claims (last consulted on 6 June 2020).

World Health Organization (2020a) 'WHO Timeline - COVID-19', World Health Organization, 27 April 2020, https://www.who.int/news-room/detail/27-04-2020-whotimeline---covid-19 (last consulted on 5 June 2020).

World Health Organization (2020b) 'Munich Security Conference', World Health Organization, www.who.int $/ \mathrm{dg} / \mathrm{speeches/detail/munich-security-conference} \mathrm{(last} \mathrm{consulted} \mathrm{on}$ 6 June 2020).

World Health Organization (2020c) 'EPI-WIN: WHO information network for epidemics', World Health Organization, www.who.int/teams/risk-communication (last consulted on 6 June 2020).

World Health Organization (2020d) 'Coronavirus disease (COVID-19) advice for the public: Myth busters', World Health Organization www.who.int/emergencies/diseases/ novel-coronavirus-2019/advice-for-public/myth-busters (last consulted on 6 June 2020).

Zarocostas, J. (2020) 'How to fight an infodemic', The Lancet 395(10225): 676, https://doi. org/10.1016/S0140-6736(20)30461-X. 